EDUR • Educação em Revista. 2021; 37:e24191

DOI: http://dx.doi.org/10.1590/0102-469824191

(9) (1) $\mathrm{https://creativecommons.org/licenses/by/4.0/}$

ARTIGO

\title{
NECESSIDADES FORMATIVAS DE PROFESSORES DE CIÊNCIAS DE ESCOLAS DO CAMPO: UMA INVESTIGAÇÃO NO SEMIÁRIDO PIAUIENSE
}

\author{
ALEXANDRE LEITE DOS SANTOS SILVA ${ }^{1}$ \\ ORCID: http://orcid.org/0000-0002-8239-9240 \\ SUZANA GOMES LOPES ${ }^{2}$ \\ ORCID: http://orcid.org/0000-0001-9071-9585 \\ EDUARDO KOJY TAKAHASHI ${ }^{3}$ \\ ORCID: http://orcid.org/0000-0003-4303-1088
}

\begin{abstract}
RESUMO: A análise das necessidades formativas docentes é fundamental para o diagnóstico, a planificação e a tomada de decisões na área da Educação. Essas necessidades podem ser definidas como preocupações, desejos, carências e problemas sentidos e percebidos no processo de ensino, representativos de valores surgidos em determinado contexto. O objetivo deste trabalho é discutir os resultados de uma pesquisa que procurou identificar as necessidades formativas de professores de Ciências de escolas do campo de um município do semiárido piauiense entre os anos de 2017 e 2018. Para isso, os dados foram coletados por meio de formulários, questionários, entrevistas e documentos. Os sujeitos que colaboraram para a pesquisa foram professores de Ciências e diretores de escolas do campo, professores e estudantes de um curso de Licenciatura em Educação do Campo com enfoque em Ciências da Natureza. A análise mostrou que os professores de Ciências das escolas do campo do estudo possuíam as necessidades de melhores condições de trabalho, de adotarem metodologias de ensino não convencionais e de saberes específicos da área de Ciências da Natureza. É ressaltado nos resultados que eles também possuíam as necessidades, embora não conscientes delas, de desenvolverem um ensino contextualizado e de saberes sobre a Educação do Campo.
\end{abstract}

Palavras-chave: Educação do Campo, ensino de Ciências, formação docente.

\section{THE NEEDS ON THE TRAINING OF SCIENCE TEACHERS IN COUNTRYSIDE SCHOOLS: AN INVESTIGATION IN THE SEMI-ARID OF PIAUÍ, BRAZIL}

\begin{abstract}
The study of needs on the training of science teachers is essential for diagnosis, planning and decision-making in the field of education. These needs can be defined as concerns, desires, necessities and problems sensed and detected in the teaching process, typical of values emerged in a given context. The purpose of this article is to examine the results of a research that intended to identify the training needs of science teachers in countryside schools of a township located in the semi-arid region of Piauí, Brazil, between 2017 and 2018. For this, data were collected through the use of forms, questionnaires, interviews and documents. The subjects who collaborated on the research were Science teachers and principals of rural schools, teachers and students from a Rural Education Program with a focus on
\end{abstract}

\footnotetext{
${ }^{1}$ Universidade Federal do Piauí (UFPI). Picos, PI, Brasil. < alexandreleite@ufpi.edu.br>

${ }^{2}$ Universidade Federal do Piauí (UFPI). Picos, PI, Brasil. < sglopes@ufpi.edu.br>

${ }^{3}$ Universidade Federal de Uberlândia (UFU). Uberlândia, MG, Brasil. <ektakahashi@gmail.com> Educação em Revista|Belo Horizonte|v.37|e24191|2021
} 
Natural Sciences. The analysis revealed that science teachers in countryside schools were in need of better working conditions, implementation of unconventional teaching methodologies and specific knowledge in the field of natural sciences. The results also remark the unaware need of developing a contextual teaching and knowledge about rural education.

Keywords: Rural Education, Science Teaching, Teacher Education.

\section{NECESIDADES DE FORMACIÓN DE PROFESORES DE CIENCIAS EN ESCUELAS RURALES: UNA INVESTIGACIÓN EN EL SEMIÁRIDO PIAUIENSE}

RESUMEN: El análisis de las necesidades de formación del profesorado es esencial para el diagnóstico, la planificación y la toma de decisiones en educación. Estas necesidades pueden definirse como preocupaciones, deseos, faltas y problemas que se sienten y perciben en el proceso de enseñanza, representativos de los valores que surgen en un contexto. El objetivo del trabajo es discutir los resultados de una investigación que buscó identificar las necesidades de formación de docentes de ciencias de escuelas rurales en un municipio del estado semiárido de Piaú entre 2017 y 2018. Para esto, los datos fueron recopilados por medio de formularios, cuestionarios, entrevistas y documentos. Los sujetos que contribuyeron para la investigación son maestros de ciencias y directores de escuelas rurales, maestros y estudiantes de un curso de licenciatura en educación rural con un enfoque en Ciencias Naturales. El análisis enseñó que los profesores de ciencias en las escuelas rurales tenían la necesidad de mejores condiciones de trabajo, de adoptar metodologías de enseñanza no convencionales y de conocimientos específicos de las Ciencias Naturales. Se destaca en los resultados que ellos también tenían las necesidades inconscientes de desarrollar la enseñanza contextualizada y el conocimiento sobre educación rural.

Palabras clave: Educación rural, Enseñanza de ciencias, Formación docente. 


\section{INTRODUÇÃO}

As pesquisas em torno da análise das necessidades educativas tiveram seu início no final da década de 1960 nos Estados Unidos (MADAUS; STUFFLEBEAM; SCRIVEN, 1983; FERNANDEZ, 1991). Essas investigações tornaram-se fundamentais para tomadas de decisões na área da Educação, para justificar gastos públicos, atender a demandas crescentes de serviços sociais e otimizar o uso dos recursos (TEJEDOR, 1990). Incluem as análises das necessidades formativas docentes, que são essenciais para o diagnóstico e o planejamento de processos de formação (RODRIGUES; ESTEVES, 1993), considerando o papel-chave dos professores em qualquer mudança que se queira fazer no sistema educacional (LIBÂNEO, 2011). Esse tipo de estudo pode produzir reflexões sobre o estado atual da educação, que podem ser tomadas como subsídios para políticas públicas.

Com isso, os objetivos deste trabalho são apresentar e discutir os resultados de uma pesquisa sobre as necessidades formativas de professores de Ciências de escolas do campo de um município ${ }^{4}$ situado na região do semiárido piauiense.

Esta pesquisa trata da educação voltada para a população campesina. Pensar a educação da população do campo é pensar também no desenvolvimento tanto do campo como da cidade (KOLLING; NERY; MOLINA, 1999). Assim, só se pode planejar o desenvolvimento de toda a sociedade se considerado também o que é produzido no campo em termos econômicos, sociais e culturais. Por isso, o estudo da formação de professores para o campo tem reflexos mais amplos, indo além da educação e do desenvolvimento da população campesina.

Para essa população, foi constatado que há, relativamente, poucas pesquisas sobre o ensino de Ciências (PAZ; USTRA, 2018; SILVA et al., 2019). Além disso, não foi encontrada nenhuma pesquisa quanto às necessidades formativas de professores do campo voltadas para o ensino de Ciências. Uma revisão de literatura em artigos dos últimos cinco anos de periódicos da área da Educação, na plataforma SciELO $^{5}$, indicou três trabalhos sobre necessidades formativas docentes (FÜRKOTTER et al., 2014; PARISOTTO; RINALDI, 2016; SORDI, 2019).

Fürkotter et al. (2014) desenvolveram uma ampla pesquisa, do tipo survey, envolvendo 10 municípios do estado de São Paulo, para identificar o perfil e as necessidades formativas dos professores municipais, da educação infantil ao ensino fundamental. Para isso, fizeram uso do questionário, cujos dados foram submetidos à análise de conteúdo. Sua investigação forneceu subsídios para a determinação de aspectos relevantes para a formação contínua de professores. Parisotto e Rinaldi (2016) procuraram entender as necessidades formativas de professores dos anos iniciais do ensino fundamental da rede pública municipal de Presidente Prudente, São Paulo, para o ensino da língua materna. A pesquisa envolveu a análise documental e a aplicação de questionários em gestores escolares e professores. As necessidades formativas emergiram a partir da expressão das dificuldades enfrentadas pelos professores, segundo o ponto de vista deles. A partir dos resultados, foi possível traçar temas e conteúdos norteadores para ações de formação continuada. Sordi (2019), através de uma investigação narrativa, analisou as necessidades formativas de professores para a docência no ensino superior e para lidar com os desafios institucionais. O seu trabalho apontou para o potencial dos espaços institucionais de apoio à docência como meios de atender às necessidades formativas dos professores universitários, especialmente na sua dimensão social.

Nesses trabalhos, as necessidades foram determinadas a partir, principalmente, de suas próprias concepções, dentro de uma perspectiva humanista ${ }^{6}$ (RODRIGUES; ESTEVES, 1993). Elas foram consideradas, de forma geral, como saberes e condições expressos pelos professores em termos de carências relacionadas a dificuldades que enfrentam no exercício da docência. Os dados foram coletados, em dois trabalhos, por meio de questionário e, em um trabalho, a partir de narrativas. Em dois

\footnotetext{
${ }^{4}$ O município não foi identificado como condição para os pesquisadores obterem a autorização da Secretaria Municipal de Educação para a realização da investigação, aprovada pelo Comitê de Ética local, na referida rede pública escolar

${ }^{5}$ Disponível no endereço eletrônico: <http://www.scielo.br/>. Acesso em: 10 ago. 2019.

"A denominação "humanista" foi dada por Rodrigues e Esteves (1993, p. 23) à perspectiva para a análise das necessidades formativas centradas na "pessoa a formar", diferente das abordagens que privilegiam a posição do formador. Os autores propõem, neste trabalho, a perspectiva dialética, que leva em conta a totalidade, isto é, tanto a pessoa a formar como o formador e outros interessados no processo de formação, além de levar em conta as contradições e as mudanças contextuais. Educação em Revista|Belo Horizonte|v.37|e24191|2021
} 
trabalhos foi utilizada a análise de conteúdo.

Este estudo poderá contribuir, em relação aos supracitados, por ter sido realizado no contexto da Educação do Campo e em um município da Região Nordeste. Além disso, partiu da perspectiva dialética, que compreende, pela noção de totalidade, que as necessidades formativas são dinâmicas, contraditórias e abrangentes. Nessa perspectiva, o problema que norteou a pesquisa foi: quais são as necessidades de formação dos professores de Ciências de escolas do campo de um município localizado no semiárido piauiense?

No seu desenvolvimento, este trabalho está organizado da seguinte forma: primeiro, apresenta o quadro teórico sobre Educação do Campo e sobre as necessidades formativas; em seguida, explica o percurso metodológico da pesquisa e expõe os resultados e discussões; consecutivamente, apresenta as considerações finais.

\title{
EDUCAÇÃO DO CAMPO E EDUCAÇÃO RURAL
}

Há dois paradigmas que disputam o espaço educacional direcionado para a população camponesa: a Educação do Campo e a Educação Rural.

\begin{abstract}
A expressão "Educação do Campo", no aparelho de Estado, substitui ainda que apenas parcialmente, a expressão "Educação Rural”, não obstante esta última denominação permanecer nas estatísticas oficiais e na maioria das políticas governamentais em andamento. Nessa luta de hegemonia, é lugar comum nas práticas de elaboração da concepção "Educação do Campo" se tomar o escopo da "Educação Rural" como referência a ser superada, teórica e politicamente. Com efeito, supostamente contrária à essência da Educação Rural, a nova concepção reivindica o sentido de educação universal e, ao mesmo tempo, voltada à construção de autonomia e respeito às identidades dos povos do campo (MUNARIM, 2010, p. 11).
\end{abstract}

A Educação Rural tem sido o paradigma educacional historicamente hegemônico no meio rural, caracterizada por sua visão retificadora, redentora, urbanocêntrica e evolucionista (RIBEIRO, 2013). Ela acredita que tem uma função retificadora, ou seja, de corrigir a situação de atraso do morador do campo. Também se vê como redentora, para suprir as carências da população do campo. É urbanocêntrica, pois o modelo de vida urbano é tratado como o ideal. Tem uma concepção evolucionista, já que trata a situação do camponês como um estado primitivo, não civilizado, que precisa partir para um estado superior, o urbano. Por conseguinte, é descontextualizada, não compreendendo e não valorizando, do ponto de vista do homem do campo, a sua realidade, a sua vida e o seu trabalho, uma vez que foi construída por interesses alheios a ele.

Por outro lado, a Educação do Campo, termo surgido no final dos anos $1990 \mathrm{com}$ as contribuições de movimentos sociais (CALDART, 2012), é um paradigma educacional contrahegemônico (FRIGOTTO, 2010) e em processo de constituição, designando a educação construída com a população camponesa. Trata-se de uma educação fundamentada na noção de complementaridade entre o campo e a cidade e no fortalecimento da identidade campesina pela criação de vínculos de pertencimento do estudante do campo com o contexto rural no qual está inserido (BRASIL, 2003). Além disso, é influenciada por diversos referenciais pedagógicos, como a pedagogia do movimento, a pedagogia socialista e a pedagogia do oprimido (CALDART, 2011). Com esses referenciais, a Educação do Campo se norteia em princípios como: (i) educação de qualidade como direito da população camponesa, com respeito à sua cultura, seus valores e seus conhecimentos; (ii) educação construída com respeito às organizações comunitárias e a seus saberes; (iii) educação organizada no espaço camponês; (iv) educação produtora de uma cultura mediada pelo trabalho na terra e para terra; (v) educação para o desenvolvimento sustentável; (vi) educação contextualizada, com respeito à heterogeneidade dos povos do campo (BRASIL, 2007). Desse modo, a proposta da Educação do Campo se baseia em uma concepção de ensino construída a partir do olhar e dos interesses do sujeito do campo, estando ancorada em importantes documentos normativos (BRASIL 1996; 2002; 2013).

Há uma dicotomia existente na educação que ocorre no meio rural do nosso país: duas escolas, dois tipos de educação que representam interesses antagônicos e diferentes modelos de desenvolvimento; um tentando negar o outro, em uma contradição dialética, assim como acontece entre 
os interesses da elite ruralista e dos representantes do agronegócio, alimentados pelo sistema capitalista, e os interesses da população campesina, constituída por pequenos agricultores, ribeirinhos, quilombolas, nações indígenas e diversos tipos de assalariados vinculados ao trabalho rural (FERNANDES, 2008). Essa contradição entre a Educação Rural e a Educação do Campo é histórica e é percebida no dinamismo das políticas educacionais e de documentos normativos, em que ora privilegiam uma excluindo a outra, ora fazem o contrário. No entanto, o que temos visto é que as vitórias da Educação Rural, hegemônica, são mais antigas e estão arraigadas na cultura escolar brasileira. Isso acontece, dentre outros motivos, porque o "governo administra o Estado apenas para favorecer a interesses de grupos econômicos e financeiros minoritários em detrimento dos serviços públicos para a população" (KOLLING; NERY; MOLINA, 1999, p. 49).

Dentro da perspectiva da Educação do Campo, surgiram, desde a década de 2000, os cursos de Licenciatura em Educação do Campo (LEdoC), sob o Programa de Apoio à Formação Superior em Licenciatura em Educação do Campo (PROCAMPO), a partir de lutas e reivindicações sociais (MOLINA; HAGE, 2015; MOLINA, 2017). Entre os mais de 40 cursos existentes, grande parte tem enfoque na área de Ciências da Natureza, cujo objetivo é formar educadores habilitados para atuarem multidisciplinarmente nessa área de conhecimento no ensino fundamental e médio em escolas do campo (HALMENSCHLAGER et al., 2017).

As LEdoCs são cursos regulares que funcionam em regime de alternância entre duas etapas de formação: o Tempo Universidade, que é quando o estudante, vinculado ao meio rural, tem aulas e atividades na universidade; e o Tempo Comunidade, que é quando os estudantes realizam atividades orientadas pelos professores universitários na comunidade onde residem ou trabalham (MOLINA, 2015). A alternância entre esses períodos tem como objetivo principal integrar os saberes universitários com os saberes camponeses, dentro da proposta do paradigma da Educação do Campo.

\section{NECESSIDADES FORMATIVAS DOCENTES}

As necessidades formativas docentes podem ser definidas como preocupações, desejos, carências e problemas sentidos e percebidos no processo de ensino, representativos de valores surgidos em determinado contexto (MESA et al., 1990). Por isso, pode-se dizer que elas são dinâmicas, sujeitas a mudanças relacionadas aos sujeitos que as expressam, ou ao lugar ou período em que são consideradas. Outrossim, podem ser representadas por saberes ou pelo "saber fazer" demandados para o processo de ensino-aprendizagem (CARVALHO; GIL-PÉREZ, 2011).

As necessidades formativas também podem incluir condições não satisfeitas e necessárias para que um indivíduo, grupo ou sistema alcance os seus objetivos ou um padrão de funcionamento ou vida normal (D’HAINAUT, 1979). Dessa forma, pode-se considerá-las não apenas como saberes, mas também como condições em que os professores os constroem. Além disso, podem referir-se a pessoas ou sistemas e ser particulares ou coletivas, conscientes ou inconscientes, atuais ou potenciais (D’HAINAUT, 1979), o que evidencia o seu caráter dual e contraditório (ANTOLÍ; MUÑOZ; RODRIGUES, 2001).

Existem vários modelos de análise das necessidades formativas (LOPEZ, 2017). Muitas vezes recorre-se aos próprios professores para identificá-las, nas abordagens ditas humanistas (MESA et al., 1990). Entretanto, não há modelos certos de análise e as escolhas metodológicas dependerão dos objetivos e dos recursos disponíveis (McKILLIP, 1987; RODRIGUES; ESTEVES, 1993).

A compreensão das necessidades depende dos valores, da cultura, do grupo social estudado e da época em que emergem, isto é, do contexto (SILVA, 2000; GALINDO, 2011). Assim, é preciso uma perspectiva totalizadora para este tipo de pesquisa, como a dialética, norteada por uma lógica "que reflete fidedignamente o movimento real das transformações que se passam no mundo exterior, físico e social" (PINTO, 1979, p. 44). Essa visão considera as contradições como os motores das transformações e determinantes da essência dos elementos que compõem a realidade em sua totalidade.

\section{PERCURSO METODOLÓGICO}

A pesquisa, realizada entre o segundo semestre de 2017 e o primeiro semestre de 2018, 
buscou recorrer a diferentes fontes de informação e instrumentos de coleta de dados. $\mathrm{O}$ estudo foi realizado em um dos municípios centrais do semiárido piauiense, escolhido por ser um local representativo na região e onde houve a autorização da Secretaria Municipal de Educação para a realização de coleta de dados nas suas escolas. Nas subseções a seguir, quanto ao percurso metodológico, serão fornecidos detalhes sobre os sujeitos da pesquisa, sobre os instrumentos de coleta e sobre a análise dos dados.

\section{Os sujeitos da pesquisa}

Os dados foram coletados com a colaboração de sujeitos dos grupos: professores de Ciências e diretores de escolas do campo, professores e estudantes de uma LEdoC ${ }^{7}$. Nos resultados e discussões, para preservar o seu anonimato, são identificados pelo grupo, seguido por um número, o instrumento de pesquisa e o período da coleta de informações.

Os endereços e contatos dos diretores e professores foram fornecidos pela Secretaria Municipal de Educação. Com base nesses contatos, as visitas foram previamente agendadas conforme os horários sugeridos pelos diretores e professores.

A pesquisa foi realizada com 11 professores de Ciências de escolas da área rural (58\% do total), porque eles são os protagonistas da investigação. A meta era atingir todas as escolas do campo da rede municipal, porém nem todas tinham professores de Ciências contratados e lotados no momento das visitas. Outros não quiseram participar da pesquisa ou não compareceram nos dias agendados nas escolas. Os professores foram incluídos devido ao entendimento de que não se pode compreender as suas necessidades formativas sem a sua própria expressão.

A maioria dos professores de Ciências que participou é do sexo feminino e reside na área urbana. A idade média deles é de 38 anos. Quanto à formação, a maioria estudou em escola pública e urbana durante a educação básica. Além disso, a maior parte é graduada em cursos de Licenciatura em Ciências Biológicas e em Instituições de Ensino Superior públicas. Quase todos os sujeitos possuem pósgraduação lato sensu, com especialização na área da Educação. Sobre a experiência profissional, os professores têm uma média de 13 anos de docência na Educação Básica, sendo nove anos no ensino de Ciências da Natureza. A maioria é servidor efetivo do município e tem carga horária semanal de 20 horas. Os sujeitos ministram uma média de 12 horas-aula de Ciências por semana nas escolas municipais da área rural. Ademais, a maior parte dos professores de Ciências possui mais de um emprego, conciliando, portanto, o trabalho em um cargo na rede pública municipal com o trabalho em escolas públicas estaduais e privadas. Os professores, em geral, trabalham os componentes curriculares segundo o conteúdo e sequência apresentados nos livros didáticos adotados, não possuindo a disponibilidade de um laboratório de Ciências ou de Informática.

Além disso, recorreu-se a 13 diretores de escolas da área rural (72\% do total), como informantes-chave. Não foi possível ter a colaboração dos diretores de todas as escolas, pois houve escolas visitadas em que ainda não havia sido feita a nomeação do diretor e alguns não demonstraram interesse em participar da pesquisa. Esses sujeitos foram incluídos porque eles representam os interesses das instituições, isto é, das escolas. Saber o lado da instituição é importante na compreensão das necessidades formativas dos professores de Ciências (BRADSHAW, 1972). Ao mesmo tempo, muitos deles também foram ou são professores, possibilitando que compreendam melhor como as exigências institucionais se chocam com a realidade do professor.

Entre os diretores inquiridos, a maioria reside na área urbana, são do sexo feminino e possuem acima de 30 anos de idade. De uma forma geral, são professores efetivos da rede escolhidos e nomeados por indicação e afinidade política. Todos possuem formação em nível superior, em diversas áreas, e a maioria tem experiência na gestão de escolas (iniciando um segundo mandato na direção escolar, não exatamente na mesma escola).

No município das escolas visitadas, há uma LEdoC, com enfoque em Ciências da Natureza, em um campus de uma universidade pública. Desse curso, recorreu-se aos docentes e aos graduandos.

Seis professores da LEdoC foram considerados informantes-chave, pois o seu trabalho visa

\footnotetext{
${ }^{7}$ Sediada no mesmo município da rede pública escolar. 
formar Educadores do Campo para o ensino de Ciências da Natureza. O curso agrega o objetivo de atender às necessidades formativas para o ensino de Ciências da Natureza e para a Educação do Campo. Além disso, os professores do curso, que funciona em regime de alternância, têm uma vivência, do Tempo Comunidade, junto às diversas comunidades rurais, compreendendo de uma forma peculiar as comunidades rurais da região e a realidade do professor de Ciências da Natureza nas escolas do campo dentro de cada área, em cada contexto escolar.

Os professores participantes da LEdoC ( $50 \%$ do quadro efetivo e ativo do curso), de diferentes áreas, foram escolhidos com base na disponibilidade e proporcionalmente ao número de professores da sua área. Assim, foram entrevistados dois pedagogos (do total de cinco), dois biólogos (do total de cinco), um físico (do total de dois) e um químico (do total de dois). São quatro do sexo feminino e cinco com idade superior a 40 anos. Apenas um deles não possui a titulação de doutor e são todos veteranos e estáveis, com mais de três anos no ensino superior. Embora nenhum dos professores tenha formação específica na área de Educação do Campo, todos possuem produção acadêmica na área - em artigos, trabalhos publicados em atas e anais eventos e capítulos de livro -, e têm projetos de pesquisa e ou extensão em andamento.

Houve a participação de 119 estudantes da LEdoC (78\% do total de estudantes matriculados). Eles foram considerados informantes-chave por vários motivos: (i) por representatividade social (THIOLLENT, 1982) das pessoas, ou seja, por serem oriundos da região, terem vivência no campo e em escolas do campo locais, representando bem as comunidades rurais da região; (ii) por conhecerem os aportes teóricos da Educação do Campo (desde as disciplinas do primeiro semestre do curso); (iii) por sua formação polivalente na área de Ciências da Natureza, que contempla os componentes curriculares de Física, Química e Biologia; (iv) pelo fato de muitos estudantes terem tido experiência na docência ou ainda atuarem como professores (nas mais diversas áreas), coordenadores pedagógicos ou diretores nas escolas do campo da região ${ }^{8}$. De uma das turmas, também foram obtidos os relatórios de Estágio Supervisionado, arquivados e fornecidos pela Coordenação de Estágio do curso.

O grupo dos estudantes da LEdoC que participou da pesquisa é composto majoritariamente por sujeitos do sexo feminino (82\%). Quanto à faixa etária, a média de idade é 30 anos. Além disso, dos sujeitos inquiridos, 31\% residem no município onde se localiza o campus da LEdoC. A maioria $(69 \%)$ vive em municípios vizinhos, todos vinculados ao campo por sua área de domicílio e/ou por experiências de formação e/ou de trabalho. Identificou-se que 59\% dos licenciandos declararam não trabalhar. Dentre os que trabalham, 20\% já atuam como educadores. Apurou-se também que 31\% dos sujeitos já possuem outra graduação.

\section{Os instrumentos de coleta de dados}

Para a coleta dos dados, foram utilizados: (i) o formulário, (ii) o questionário e (iii) a entrevista; que seguiram um mesmo roteiro simples de questões, que solicitava dados sobre faixa etária, gênero, área de domicílio, formação acadêmica, experiência profissional e a opinião sobre quais seriam as necessidades formativas dos professores de Ciências nas escolas do campo locais. Os dados também foram coletados através de (iv) relatórios de Estágio Supervisionado, tratados como documentos de pesquisa.

O formulário, aplicado em professores de Ciências e em diretores de escolas do campo, é um instrumento de coleta de dados que constituiu um conjunto de questões preenchido pelo próprio pesquisador à medida que observa ou recebe as respostas (MARCONI; LAKATOS, 2003). Foi escolhido pelos pesquisadores devido à resistência dos sujeitos à gravação das entrevistas. A sua aplicação foi feita individualmente nas escolas, no intervalo entre as aulas, no segundo semestre de 2017, durante a visitação que foi feita a 16 escolas do campo do município (de um total de 27 escolas) que ofertam o ensino fundamental II.

O questionário é uma lista de perguntas e geralmente é preenchido pelos inquiridos sem a

\footnotetext{
${ }^{8}$ As LEdoCs foram implementadas para atender também as necessidades de educadores em exercício em escolas do campo sem formação universitária, algo comum no contexto campesino brasileiro. Apesar disso, havia alunos da LEdoC que possuíam graduação em Pedagogia, Ciências Biológicas e outras áreas. É comum haver diretores, na rede municipal do contexto da pesquisa, sem uma formação universitária, nomeados com base em laços políticos.

Educação em Revista|Belo Horizonte|v.37|e24191|2021
} 
presença do pesquisador (MARCONI; LAKATOS, 2003). A vantagem do uso do questionário está na sua relativa objetividade e no seu potencial de permitir a coleta de dados de um número maior de sujeitos em comparação com outras técnicas. Por isso, esse instrumento foi aplicado em estudantes de uma LEdoC durante o Tempo Universidade no primeiro semestre de 2018.

A entrevista é uma interação gravada, através da comunicação verbal, entre dois ou mais indivíduos (MINAYO, 2009). A entrevista é uma técnica adequada para conseguir informações mais profundas de uma pessoa, como representações, sentimentos, expectativas, dificuldades, formas em que se manifestam as necessidades formativas (RODRIGUES; ESTEVES, 1993). Por meio desse instrumento, foram ouvidos os professores universitários de uma LEdoC no segundo semestre de 2017.

A pesquisa foi complementada com a análise de documentos (CELLARD, 2008). Como documentos, foram analisados os relatórios de estágio, do componente curricular de Estágio Supervisionado, elaborados por estudantes da LEdoC. Nesse sentido, foram selecionados os relatórios de uma turma de 22 estudantes que fizeram o estágio de observação e de regência nas aulas de Ciências no ensino fundamental II, distribuídos em dez escolas do campo no segundo semestre de 2017. Nesses relatórios, os licenciandos registraram dados das escolas e dos professores supervisores, bem como as suas inferências quanto ao observado nas aulas e quanto à sua experiência na regência, contribuindo com dados sobre as condições de trabalho docente e sobre as práticas de ensino de Ciências locais.

Como explanado nos parágrafos anteriores, além de se obter os dados dos próprios professores de Ciências, eles também foram coletados por meio de informantes-chave (diretores escolares, professores e estudantes de uma LEdoC), isto é, pessoas que detêm um conhecimento sobre determinada comunidade estudada, podendo fornecer subsídios para a compreensão das suas necessidades educativas 9 (RODRIGUES; ESTEVES, 1993).

\section{A análise dos dados}

Diante de tantos dados coletados, foi imprescindível eleger um modelo de análise. Utilizouse como referência o texto de Creswell (2008) para o estabelecimento das seguintes subetapas: (i) a exploração, (ii) a codificação, (iii) a hierarquização e (iv) a representação.

$\mathrm{Na}$ etapa da exploração, realizou-se a leitura das transcrições das entrevistas, das respostas ao questionário e aos formulários e dos textos dos relatórios de estágio. As transcrições passaram por um processo de textualização, para eliminar as características de oralidade que dificultariam a compreensão dos textos. Durante a leitura, procurou-se identificar as necessidades formativas dos professores de Ciências de escolas do campo.

A codificação foi um processo de segmentação (divisão do texto em trechos) e marcação do texto, a fim de identificar as necessidades formativas apontadas pelos professores de Ciências e pelos informantes-chave. Nessa etapa, foram marcadas as palavras e expressões que as representavam.

$\mathrm{Na}$ hierarquização, houve o estabelecimento de relações entre as necessidades formativas identificadas, relacionando as mais gerais e as mais específicas. Desse modo, foi possível agrupá-las.

$\mathrm{Na}$ representação dos dados foi utilizado o critério da frequência, expressa em porcentagem $^{10}$, de menção das necessidades formativas dos professores de Ciências de escolas do campo, para estabelecer uma ordem de apresentação, como em Rodrigues e Esteves (1993). Para os cálculos estatísticos e construção de planilhas e gráficos, no estudo foi utilizado o programa Excel.

A análise foi complementada com elementos teóricos do Círculo de Bakhtin, dado o seu caráter dialético, para enriquecer o diálogo entre os dados coletados e o referencial teórico (VOLÓCHINOV, 2018; BAKHTIN, 2016). Assim, foram adotados conceitos como discurso, enunciado, gênero do discurso, dialogismo e polifonia (SILVA, 2013), dentre outros, importantes para a

\footnotetext{
${ }^{9}$ Nessa concepção, os professores de Ciências podem ser considerados informantes-chave. Neste trabalho, no entanto, são considerados como informantes-chave os sujeitos que não fazem parte do grupo dos professores de Ciências de escolas do campo, mas que estão familiarizados com o seu trabalho, como os diretores de escolas do campo, estudantes e professores de uma LEdoC.

${ }^{10}$ Embora as amostras de professores da LEdoC, de diretores escolares e de professores de Ciências possam ser consideradas pequenas para o tratamento estatístico, ele foi adotado para fins de comparação entre os grupos e com o grupo maior, constituído pelos estudantes da LEdoC, assim como se deu nos estudos relatados por Rodrigues e Esteves (1993).

Educação em Revista|Belo Horizonte|v.37|e24191|2021
} 
análise dos enunciados e para a correlação deles com os seus contextos e com as ideologias por trás dos paradigmas da Educação Rural e da Educação do Campo.

\section{RESULTADOS E DISCUSSÕES}

Nesta seção, apresentaremos, primeiramente, as necessidades formativas apontadas pelos diversos grupos de sujeitos participantes da pesquisa. Em seguida, sublinharemos aquelas que mais se aproximam do paradigma da Educação do Campo.

\section{Principais necessidades formativas apontadas}

Os professores de Ciências de escolas do campo que participaram da pesquisa, ao serem questionados sobre as suas necessidades formativas, mencionaram apenas: melhores condições de trabalho (91\%); adoção de metodologias não convencionais de ensino (73\%); e saberes específicos da área de Ciências da Natureza (73\%). Contudo, os informantes-chave mencionaram, além dessas, outras necessidades como a de se contextualizar o ensino e os saberes sobre a Educação do Campo - conforme a Tabela 1 , com as porcentagens de respostas, onde $\mathbf{n}$ representa o total de informantes de cada grupo.

TABELA 1. Necessidades formativas dos professores de Ciências segundo os informantes-chave.

\begin{tabular}{lccc}
\hline $\begin{array}{c}\text { Necessidades formativas } \\
\text { dos professores de } \\
\text { Ciências de escolas do } \\
\text { campo }\end{array}$ & $\begin{array}{c}\text { Diretores de } \\
\text { escolas do } \\
\text { campo } \\
(\boldsymbol{n}=\mathbf{1 3})\end{array}$ & $\begin{array}{c}\text { Licenciandos da } \\
\text { LEdoC } \\
(\boldsymbol{n}=\mathbf{1 1 9})\end{array}$ & $\begin{array}{c}\text { Professores da LEdoC } \\
(\boldsymbol{n}=\mathbf{6})\end{array}$ \\
\hline $\begin{array}{l}\text { Saber fazer um ensino } \\
\text { contextualizado }\end{array}$ & $46 \%$ & $89 \%$ & $83 \%$ \\
$\begin{array}{l}\text { Adoção de metodologias } \\
\text { de ensino não } \\
\text { convencionais }\end{array}$ & $69 \%$ & $33 \%$ & $100 \%$ \\
$\begin{array}{l}\text { Saberes específicos da área } \\
\text { de Ciências da Natureza }\end{array}$ & $15 \%$ & $34 \%$ & $83 \%$ \\
$\begin{array}{l}\text { Saberes sobre a Educação } \\
\text { do Campo }\end{array}$ & $0 \%$ & $36 \%$ & $17 \%$ \\
\hline $\begin{array}{l}\text { Melhores condições de } \\
\text { trabalho }\end{array}$ & $62 \%$ & $9 \%$ & $50 \%$ \\
\hline Não opinaram & $23 \%$ & $0 \%$ & $0 \%$ \\
\hline
\end{tabular}

Fonte: Dados da pesquisa (2018).

O ensino contextualizado refere-se àquele que parte da realidade dos estudantes do campo, embora na literatura acadêmica seja reconhecida a polissemia do termo (KATO; KAWAZAKI, 2011). Metodologias de ensino não convencionais foram comentadas pelos informantes-chave e pelos professores de Ciências como as que vão além de aulas expositivas, como o ensino com projetos interdisciplinares, o ensino com pesquisa, a aprendizagem baseada em problemas, o ensino por investigação, o uso de novas tecnologias digitais da informação e comunicação, os jogos didáticos, as dinâmicas de grupo e aulas práticas, sobretudo experimentos de Ciências. Os saberes específicos da área de Ciências da Natureza, mencionados pelos informantes-chave e pelos professores de Ciências, foram variados, como saberes sobre botânica, biotecnologia, energia solar, fontes de energia, alimentação saudável, sexualidade, tratamento de resíduos sólidos e temas atuais de Ciências veiculados pela mídia, algo que os estudantes veem na internet e na televisão e trazem como questionamento para a sala de aula. Os saberes sobre Educação do Campo, mencionados apenas pelos informantes-chave, referem-se aos fundamentos, aos princípios e à história de lutas que cercam esse paradigma educacional. As alusões a melhores condições de trabalho, apresentadas pelos informantes-chave e pelos professores de Ciências, foram relacionadas à necessidade de laboratórios de Ciências, maior espaço na escola para a realização de projetos e recursos didáticos como livros, recursos tecnológicos e materiais para a realização de 
experimentos de Ciências. Também sobre melhores condições de trabalho, além de infraestrutura e recursos didáticos, foi mencionada a necessidade de formação continuada.

A necessidade formativa de saberes sobre a Educação do Campo só foi mencionada por sujeitos vinculados à LEdoC. Um resultado relevante deste trabalho é que os informantes-chave apontaram mais necessidades formativas que os professores de Ciências de escolas do campo, o que ressalta a importância da perspectiva dialética. Duas necessidades não foram apontadas pelos professores de Ciências: saberem desenvolver um ensino contextualizado e saberes sobre a Educação do Campo. Devido à proximidade de tais necessidades ao paradigma da Educação do Campo, voltado para um ensino contextualizado à realidade do campo e para uma formação de professores que considere as peculiaridades campesinas, elas constituem o foco das discussões a seguir.

\section{Necessidade formativa de saber fazer um ensino de Ciências contextualizado}

Quanto à necessidade de saber fazer um ensino de Ciências contextualizado, os trechos a seguir, retirados das respostas de alguns informantes, foram representativos:

Os professores precisam trabalhar temas do cotidiano: água, coleta de lixo, dengue, para contextualizar. (Diretor escolar 02, Formulário, 2017).

Deveria ser voltado para as pessoas do campo, algo que tenha a ver com o cotidiano da área rural. (Estudante da LEdoC 41, Questionário, 2018).

Contextualizado, privilegiando os sujeitos do campo, respeitando suas características, socializando e efetivando métodos para que o estudante da escola do campo sinta-se parte dos processos e que tenha garantia de ensino que vá contribuir com sua formação. Uma formação mais voltada para a realidade da escola do campo, que se aproxime das condições e da realidade que o professor irá encontrar na escola do campo. (Estudante da LEdoC 67, Questionário, 2018).

[...] toda metodologia deveria começar pelo contexto de vida do sujeito [...] vivemos em um sistema capitalista que impede um atendimento individualizado. A massificação impede que o professor trate o estudante individualmente, que é um princípio de uma educação de qualidade [...] começar pelo contexto de vida do sujeito. O ensino devia começar com a exploração do que o estudante vive, do que o estudante pensa sobre o lugar onde ele vive e das experiências que o estudante já viveu naquele lugar, principalmente relacionadas à natureza. (Professor da LEdoC 03, Entrevista, 2017).

O professor e os estudantes da LEdoC usam termos comuns como "do campo", "realidade" e "sujeito" ao se referirem à contextualização. Os vocábulos e o fato de se relacionarem no mesmo curso voltado para a Educação do Campo caracterizam esses discursos como resultados de interações dialógicas, ou seja, mesmo que esses discursos não estejam no contexto de um diálogo direto entre interlocutores, como destinatários concretos, eles dialogam entre si e dialogam com outros discursos falados ou escritos no âmbito da Educação do Campo. Também associam a contextualização com a "formação" ou a "educação". Dessa forma, a contextualização está ligada, em ambos os enunciados, não apenas por um vocabulário comum, mas também por objetivos comuns, aproximando-se de um mesmo gênero discursivo (BAKHTIN, 2016).

Os enunciados dos sujeitos sobre a necessidade de os professores de Ciências do campo locais fazerem um ensino contextualizado condizem com as discussões sobre o paradigma da Educação do Campo. A construção histórica do conceito Educação do Campo "convocou a escola e seus profissionais a dialogar com o mundo do campo e com seus sujeitos sociais, a construir uma escola diferenciada e contextualizada na vida, no trabalho e na cultura do povo" (MOLINA, 2006, p. 90). Esse povo, na verdade, são povos, que se caracterizam por uma diversidade de grupos e de lugares, cuja vida, trabalho e cultura respondem por saberes. Nessa direção, contextualizar, no ensino, é provocar o diálogo na relação dialética entre esses saberes e o saber sistematizado. Como expressou Freire (2013, 2013, p. 31):

Por isso mesmo pensar certo coloca ao professor ou, mais amplamente, à escola, o dever de não só respeitar os saberes com que os educandos, sobretudo os das classes populares, chegam a ela 
- saberes socialmente construídos na prática comunitária - mas também, como há mais de trinta anos venho sugerindo, discutir com os estudantes a razão de ser de alguns desses saberes em relação com o ensino dos conteúdos.

Por conseguinte, a criação desse diálogo pelo professor no ensino de Ciências é um meio de mostrar respeito aos saberes do educando e, finalmente, à sua vida, ao seu trabalho e à sua cultura.

Além disso, contextualizar é tomar algo do cotidiano do estudante, com o qual ele tenha familiaridade, como ponto de partida para o ensino através do estabelecimento de relações, como associações e comparações (LIMA; PAULA; SANTOS, 2009). Essas relações de ancoragem dos novos conhecimentos a conhecimentos já existentes são condições para uma aprendizagem significativa (AUSUBEL; NOVAK; HANESIAN, 1980). Entretanto, a contextualização, mais que um ponto de partida, deve possibilitar o desenvolvimento de atividades sociais, culturais e produtivas no meio rural, junto com a reflexão crítica e a aplicação do saber sistematizado a problemas locais para neles intervir, propiciando uma troca de saberes entre dois polos: a academia e a comunidade rural (LIMA, 2014; LEITE; RADETZKE, 2017). Para isso, a contextualização deve abarcar mais que a dimensão metodológica, perpassando também as dimensões histórica e socioambiental (GONZÁLEZ, 2004).

O fato de os professores de Ciências não terem mencionado essa necessidade reflete a sua inconsciência dela. Conforme D’Hainaut (1979), há necessidades inconscientes, pois nem sempre os sujeitos se dão conta do que realmente precisam para a sua formação e para a realização do seu trabalho. Muitas vezes carecem de maturidade e de conhecimentos para isso (RODRIGUES; ESTEVES, 1993). Em um estudo sobre as necessidades de formação de professores de Ciências no contexto iberoamericano, foi registrado:

Quando se solicita a um professor em formação ou em exercício que expresse sua opinião sobre “o que nós, professores de Ciências, deveríamos conhecer - em um sentido mais amplo de 'saber' e 'saber fazer' - para podermos desempenhar nossa tarefa e abordar de forma satisfatória os problemas que esta nos propõe", as respostas são, em geral, bastante pobres e não incluem muitos dos conhecimentos que a pesquisa destaca hoje como fundamentais [...] Pode-se chegar assim à conclusão de que nós, professores de Ciências, não só carecemos de uma formação adequada, mas não somos sequer conscientes das nossas insuficiências (CARVALHO; GILPÉREZ, 2011, p. 14).

Portanto, os professores de Ciências nem sempre têm consciência de suas necessidades formativas, o que torna relevante diversificar as fontes de informação.

A não menção, pelos professores, da contextualização no ensino revela a existência de uma prática de ensino desvinculada da realidade dos seus estudantes, o que foi corroborado pela análise dos relatórios de observação dos estagiários. Por isso, alguns estagiários refletiram:

É necessário que o professor crie situações comuns do dia a dia do estudante, trazendo para a sala de aula e aproximando aos conhecimentos científicos. (Estudante da LEdoC 11, Relatório de Estágio Supervisionado, 2017).

Faltou contextualização nas aulas da professora [...]. (Estudante da LEdoC 10, Relatório de Estágio Supervisionado, 2017).

Desse modo, a contextualização não está presente na prática, embora, teoricamente, há mais de 20 anos, os Parâmetros Curriculares Nacionais apontem para a sua importância no ensino, não somente para os estudantes da área rural, mas em todos os contextos (BRASIL, 1997). Conforme Cortez e Darroz (2017), a contextualização, contraditoriamente, não é uma realidade concreta nos meios escolares brasileiros. Para que isso aconteça, o professor precisa ser também um pesquisador da prática social, das riquezas naturais, dos problemas ambientais locais e regionais, do trabalho, dos interesses, da cultura, dos valores e dos saberes das comunidades rurais que atende. De posse desse conhecimento da realidade dos estudantes, o professor de Ciências pode ter os recursos necessários para problematizar e provocar a reflexão sobre ela.

A inconsciência dos professores de Ciências quanto à necessidade de um ensino contextualizado ao meio rural é uma evidência da sua falta de conexão como o paradigma contra- 
hegemônico da Educação do Campo.

\section{Necessidade formativa de saberes sobre a Educação do Campo}

Quanto à necessidade de saberes sobre a Educação do Campo, alguns sujeitos expressaram:

Primeiro, os fundamentos da Educação do Campo que eu acredito que ainda não estão bem alicerçados, principalmente nessa formação, porque o curso de Licenciatura em Educação do Campo é muito recente. Então, os professores que atuam em escolas do campo ensinando Ciências da Natureza, eles não têm a fundamentação teórica e metodológica da Educação do Campo, próprios da área de conhecimento [...]. (Professor da LEdoC 05, Entrevista, 2017).

Uma formação com objetivos voltados para os sujeitos do campo[...]. (Estudante da LEdoC 31, Questionário, 2018).

Necessitam de instruções diferenciadas da área urbana, ou seja, precisam aperfeiçoar os seus conhecimentos na área rural, assim como o que está acontecendo conosco, o nosso curso ensina como ser um professor do campo para estudantes do campo. (Estudante da LEdoC 32, Questionário, 2018).

Percebe-se que a necessidade de saberes sobre a Educação do Campo foi mencionada apenas por informantes-chave vinculados à LEdoC, seus professores e estudantes. É um fato compreensível, já que fazem parte de um mesmo grupo em que tais saberes, na forma de discursos, circulam (BAKHTIN, 2016). Essa constatação indica também que esses discursos não têm chegado ao âmbito dos professores de Ciências e diretores de escolas do campo locais, apontando uma contradição entre a teoria e a prática. Embora o conceito Educação do Campo tenha se desenvolvido há mais de 20 anos e esteja presente em documentos oficiais, na prática é desconhecido ou não considerado por educadores que trabalham nas áreas rurais.

Essa necessidade também foi apontada por Alencar (2015) no seu estudo com professores de uma escola de um assentamento agrícola. Ele concluiu que, apesar do desenvolvimento da Educação do Campo sob a bandeira dos movimentos sociais, os professores por ele investigados estavam submergidos em uma realidade educacional e em uma formação alheias a essa questão, uma situação contraditória de uma escola edificada em um assentamento originado de um movimento social de trabalhadores rurais. Um de seus apontamentos, por conseguinte, foi que "os educadores do campo precisam ter oportunidades de formação continuada específica na educação do campo" (ALENCAR, 2015, p. 57).

O reconhecimento da necessidade de saberes sobre Educação do Campo requer o reconhecimento da situação de opressão do camponês (FREIRE, 2013). Para reconhecer e superar tal opressão, é preciso uma educação que parta de aspectos concretos das necessidades sentidas pelos camponeses (PACHECO, 2017).

Os saberes sobre a Educação do Campo emergem da realidade e das necessidades do povo camponês, que, portanto, devem ser apreendidas. Envolvem a familiarização com o seu ecletismo pedagógico e saberes oriundos da relação com os movimentos sociais e do reconhecimento e valorização da diversidade social e cultural, expressa através do trabalho, da cultura, das lutas e dos modos de vida camponeses. Portanto, são saberes entrelaçados não apenas com a teoria advinda da prática educativa do campo, nos espaços escolares, nos mais diversos lugares, e presentes em textos de livros, de periódicos e de trabalhos apresentados em eventos acadêmicos. Estão entrelaçados também com os saberes sociais produzidos no trabalho, na terra, nas tradições e nos movimentos sociais. Esses saberes não foram encontrados entre os professores de Ciências das escolas do campo locais, que, em nenhum momento, usaram a expressão "Educação do Campo". Percebe-se também nos seus enunciados:

[o ensino de Ciências] É normal, no campo é como na cidade. (Professor de Ciências 10, Formulário, 2017).

A diferença [entre escola urbana e rural] quem faz é o professor. Sempre procuro fazer as mesmas atividades, trabalhos, testes, na área rural como também na urbana. (Professor de 
Ciências 11, Formulário, 2017).

Acredito que não há muita diferença [entre escolas rurais e urbanas] [...]. (Professor de Ciências 05, Formulário, 2017).

De acordo com os enunciados acima, para os professores de Ciências, o ensino no campo e no meio urbano não tem diferença, isto é, não há distinção entre eles, o que coloca o seu ponto de vista sob o paradigma da Educação Rural. A perspectiva urbanocêntrica se mostra nos enunciados através da preposição "como": a escola do campo como na cidade, o professor do campo como na cidade, o ensino de Ciências da Natureza no campo como na cidade, o estudante do campo como o da cidade. Essa perspectiva está presente de várias formas: no planejamento do ensino, na metodologia e nos materiais didáticos utilizados, nos tipos de avaliação, etc. Assim, é natural, para os jovens do campo, no município estudado, concluir a educação básica na cidade. Nela, segundo o relato de estagiários, os jovens do campo não gostam de ser identificados como "do campo". Além disso, as sessões de planejamento e formação de professores são conjuntas e as orientações para os professores das escolas do campo são as mesmas para os professores da área urbana. Outro exemplo é o livro didático. Todas as escolas, na área urbana e na área rural, adotam a mesma coleção de livros. Por conseguinte, os professores de Ciências, no campo e na cidade, utilizam o mesmo livro didático, que é, muitas vezes, o direcionador do planejamento do ensino (DELIZOICOV; ANGOTTI; PERNAMBUCO, 2011).

O livro didático não é adequado à realidade do campo. As imagens e a linguagem mostram-se distantes de uma realidade rural, e não desenvolve conceitos e reflexões acerca do contexto do campo [...] As imagens e gravuras que são apresentadas pelo livro não dialogam com a realidade vivenciada pelos estudantes do campo e a professora não busca contextualizar os conteúdos das suas aulas. (Estudante da LEdoC 19, Relatório de Estágio Supervisionado, 2017).

Tal livro [didático de Ciências] não é adaptado às escolas do campo. Este material apresenta clareza, simplicidade, possui algumas ilustrações e imagens, linguagem conceitual, apresenta proposta de problematização, contém também exercícios e sugestões para serem trabalhados em cada conteúdo, porém é voltado mais para as escolas urbanas (a maioria dos exemplos citados no livro são voltados para as cidades grandes fugindo, assim, da realidade vivenciada pelos estudantes do campo). Com isso, a professora de Ciência tenta trazer para suas aulas, da melhor maneira possível, exemplos voltados para a realidade dos estudantes da escola, para que, assim, o estudante entenda o conteúdo de forma mais clara e possua um maior aprendizado. (Estudante da LEdoC 18, Relatório de Estágio Supervisionado, 2017).

Dessa forma, os estagiários observaram o "distanciamento do ensino rural em relação à realidade do trabalho, da vida e da cultura dos estudantes das escolas rurais" (RIBEIRO, 2013, p. 177). A centralização do ensino no livro didático só reforça essa situação, pois "a grande maioria dos materiais didáticos disponíveis nas escolas é descontextualizada, portanto pouco contribui na realização de um trabalho pedagógico numa perspectiva que envolva os aspectos geoambientais do semiárido" (LIMA; MENDES SOBRINHO, 2008, p. 155).

O tratamento da educação que ocorre no campo, como não diferente da educação que ocorre no meio urbano, é algo convenientemente ignorado, isto é, visto como algo natural, como revelam as palavras "sempre" e "normal" nos enunciados dos professores de Ciências 10 e 11. Essa é uma característica do poder da ideologia, de fazer um pensamento parecer normal, natural, permanente, inquestionável, enfim, como algo que todo mundo acredita e deve ser acreditado (VOLÓCHINOV, 2018; GIROUX, 1997). Os discursos também evidenciam a influência da ideologia hegemônica que inspira a Educação Rural, advinda das classes dominantes, daqueles que se interessam por uma escola que produz para o capital, para a formação de força de trabalho excedente nas cidades e para a industrialização do campo. Vista como natural ou ignorada, essa ideologia escapa à consciência e se manifesta no discurso como algo indiscutível, natural, que passa despercebido. Conforme Volóchinov (2018), a ideologia se manifesta na linguagem. A naturalização da educação urbana no campo e a ausência da Educação do Campo no discurso dos professores de Ciências das escolas do campo são indícios de que eles foram ceifados pela ideologia que sustenta o paradigma da Educação Rural. Os saberes sobre a Educação do Campo emergiram dos movimentos sociais, mas não foi vista nenhuma relação deles com 
as escolas do campo locais. Sobre esse assunto, alguns professores de Ciências disseram:

Atuo apenas como professora [...] não tenho [ligação com os movimentos sociais]. (Professor de Ciências 10, Formulário, 2017).

Se há algum movimento, nunca fiquei sabendo [...]. (Professor de Ciências 02, Formulário, 2017).

Há, portanto, um distanciamento em relação aos movimentos sociais, o que é uma perda, dado o seu caráter pedagógico para a produção e difusão dos saberes sobre a Educação do Campo (CALDART, 2012). Dessa forma, a educação escolar que ocorre no campo, no contexto da pesquisa, apartada dos saberes que os movimentos sociais do campo produzem e sob a égide de uma administração educacional urbanocêntrica, dificilmente conseguirá desenvolver uma identidade com a Educação do Campo.

As atividades de alguns movimentos campesinos sociais locais e a sua comunicação com os trabalhadores rurais ocorrem, principalmente, por meio do rádio e das redes sociais, especialmente, com os pequenos agricultores afiliados. As interações com eles ocorrem no âmbito das assembleias sindicais e em outros eventos promovidos pelos movimentos sociais, muitas vezes distantes do espaço escolar. Soma-se a isso, no caso dos professores de Ciências, que a maioria deles, com base nos dados dos formulários, não vive no campo, intensificando esse distanciamento físico, social e cultural, já que as suas associações, atividades extraescolares e identidade acabam se ligando mais ao seu lugar - a cidade. Dessa forma, as barreiras comunicativas e a situação de domicílio da maioria dos professores de Ciências acabam por dificultar a sua parceria com os movimentos sociais, o que, por sua vez, distancia o ensino de Ciências da Natureza dos saberes da Educação do Campo.

\section{CONSIDERAÇÕES FINAIS}

Por meio desta pesquisa foi possível constatar que os professores de Ciências das escolas do campo do estudo possuem as necessidades formativas de melhores condições de trabalho, de adotarem metodologias de ensino não convencionais, de saberes específicos da área de Ciências da Natureza, mas, especialmente, de desenvolver um ensino contextualizado e de saberes sobre a Educação do Campo.

A partir dos dados, é perceptível que há pontos de vista similares quanto a necessidades formativas, mostrando que grupos de um mesmo contexto tendem a ter opiniões parecidas, o que se mostra através de enunciados que podem ser rotulados sobre um mesmo gênero discursivo, como um espectro característico, indicando valores e modos de vida compartilhados.

Há uma contradição entre os documentos normativos e a prática social (a partir dos enunciados, relatos de estagiários, observação direta nas visitações, etc.), em que os direitos dos professores e de escolas do campo, embora garantidos, não são realmente atendidos. Outra contradição se vê entre o paradigma da Educação do Campo, defendido na academia por intermédio da LEdoC, e o paradigma hegemônico da Educação Rural, enraizado nas escolas rurais municipais.

O ensino tradicional de Ciências nas escolas do campo, através da educação bancária, livresca e classificatória, é praticado sob o distanciamento dos professores em relação aos princípios e aos fundamentos da Educação do Campo. Assim, a carência maior percebida não é de infraestrutura ou recursos materiais, mas de reflexão crítica e de sua consequência: um espírito transformador. Há uma necessidade formativa de conscientização para a transformação da escola e superação do paradigma da Educação Rural.

Para os professores de Ciências de escolas do campo, essa pesquisa mostra que precisam da contribuição de outros atores, envolvidos e entremeados ao seu trabalho, na definição do que realmente necessitam no que se refere à formação. Em termos de Educação do Campo, ficou evidente o quanto é necessária a proximidade deles com os movimentos sociais. Como intelectuais críticos e transformadores, os professores precisam estar envolvidos coletivamente nas lutas sociais em prol de uma educação construída pelos trabalhadores do campo, já que eles fazem, organicamente, parte dessa classe.

Para a pesquisa educacional, este trabalho contribui para aflorar mais discussões sobre a importância do ensino de Ciências da Natureza na Educação do Campo e do papel da formação docente nessa área. A Educação do Campo é importante para toda a sociedade, pois campo e cidade fazem parte 
de uma mesma totalidade e um projeto de desenvolvimento deve incluir a todos, com toda a sua diversidade.

Localmente, os dados da pesquisa são relevantes no sentido de fornecerem subsídio para programas de formação de professores de escolas do campo. Dito isso, aponta-se como premente o planejamento de processos formativos, na modalidade de formação continuada, voltados para o ensino contextualizado e para a discussão e reflexão crítica sobre os aportes teóricos da Educação do Campo. Esses momentos formativos também podem ser ocasiões para a promoção de encontros enriquecedores e para a aproximação da escola, especialmente dos professores, com as Instituições de Ensino Superior, com a comunidade e com os movimentos sociais camponeses.

\section{REFERÊNCIAS}

ALENCAR, Ricardo L. Escola Municipal Rural Maringá, em Araguatins-TO: um estudo de caso qualitativo dos processos e necessidades de formação docente. 2015. Dissertação (Mestrado em Educação). Santa Maria: Universidade Federal de Santa Maria, 2015.

ANTOLÍ, Vicente B.; MUÑOZ, Francisco I.; RODRIGUEZ, Beatriz F. Necesidades y propuestas de formación del profesorado novel de la Universitad de Barcelona. Profesorado. Revista de Currículum y Formación del Profesorado, Barcelona, v. 5, n. 2, p 1-24, 2001. Disponível em: http:<//www.redalyc.org/pdf/567/56750205.pdf>. Acesso em: 11 ago. 2019.

AUSUBEL, David P.; NOVAK, Joseph D.; HANESIAN, Helen. Psicología educacional. 2. ed. Tradução de Eva Nick, Heliana B. C. Rodrigues, Luciana Peotta, Maria A. Fontes e Maria G. R. Maron. Rio de Janeiro: Interamericana, 1980.

BAKHTIN, Mikhail. Os gêneros do discurso. Tradução de Paulo Bezerra. São Paulo: Editora 34, 2016.

BRADSHAW, Jonathan A. Taxonomy of Social Need. In: McLACHLAN, Gordon (Ed.) Problems and progress in medical care: essays on current research. 7. ed. Londres: Oxford University Press, 1972. p. 71-82.

BRASIL. Lei n. 9394, de 20 de dezembro de 1996. Estabelece as diretrizes e bases da Educação Nacional. Brasilia, DF: 1996.

. MEC/SEF. Parâmetros Curriculares Nacionais: introdução aos parâmetros curriculares nacionais. Brasilia, DF: 1997.

. Resolução CNE/CEB n.1, de 03 de abril de 2002. Estabelece as diretrizes para a Educação Básica nas escolas do campo. Brasília, DF: 2002.

MEC/Grupo Permanente de Trabalho de Educação do Campo. Referências para uma política nacional de Educação do Campo. Caderno de Subsídios. Brasília, DF: 2003.

DF: 2007.

. MEC/SECADI. Educação do Campo: diferenças mudando paradigmas. Cadernos Secadi. Brasília,

MEC/SEB/SECADI/SEPT/CNE/CNEB. Diretrizes Curriculares Nacionais Gerais da Educação Básica. Brasília, DF: MEC, SEB, DICEI, 2013.

CALDART, R. S. Por uma educação do campo: traços de uma identidade em construção. In: ARROYO, M. G.; CALDART, R. S.; MOLINA, M. C. (Orgs.) Por uma educação do campo. 5. ed. Petrópolis: Vozes, 2011. p. 147-160. 
Janeiro/São Paulo: Escola Politécnica de Saúde Joaquim Venâncio, Expressão Popular, 2012. p. 257-265.

CARVALHO, Anna M. P.; GIL-PÉREZ, Daniel. Formação de professores de ciências: tendências e inovações. 10. ed. São Paulo: Cortez, 2011. (Coleção Questões da Nossa Época, 28).

CELLARD, Andre. Análise documental. In: POUPART, Jean et al. A pesquisa qualitativa: enfoques epistemológicos e metodológicos. Tradução de Ana C. Nasser. Petrópolis: Vozes, 2008. p. 295-316.

CORTEZ, Jucelino; DARROZ, Luiz M. A contextualização no ensino de ciências na visão de professores da educação básica. Revista Thema, Pelotas, v. 14, n. 3, p. 182-190, 2017. Disponível em: <http://dx.doi.org/10.15536/thema.14.2017.182-190.533>. Acesso em: Acesso em: 8 jul. 2020.

CRESWELL, John W. Educational research: planning, conducting, and evaluating quantitative and qualitative research. 3. ed. Columbus, Ohio, U.S.A.: Pearson, 2008.

DELIZOICOV, Demetrio; ANGOTTI, Andre J.; PERNAMBUCO, Marta M. Ensino de Ciências: fundamentos e métodos. 4. ed. São Paulo: Cortez, 2011.

D'HAINAUT, Louis. Les besoins en education. In: (Coord.). Programmes d'études et education permanente. Paris: UNESCO, 1979. p. 62-80.

FERNANDES, Bernardo M. Educação do campo e território camponês no Brasil. In: SANTOS, C. A. (Org.). Por uma educaşão do campo: campo - políticas públicas - educação. Brasília: Incra, MDA, 2008. p. 39-66. (Coleção Por Uma Educação do Campo, 7).

FERNANDEZ, María J. M. T. Metaevaluación de necesidades educativas: hacia un sistema de normas. 1991. Tesis (Doctorado). Facultad de Filosofía y Ciencias de la Educación, Universidad Complutense de Madrid, Madrid, España, 1991.

FREIRE, Paulo. Pedagogia do oprimido. 54. ed. Rio de Janeiro: Paz e Terra, 2013.

FRIGOTTO, Gaudêncio. Projeto societário contra-hegemônico e educação do campo: desafios do conteúdo, método e forma. In: MUNARIM, A. et al. (Orgs.). Educação do campo: reflexões e perspectivas. Florianópolis: Insular, 2010. p. 19-46.

FÜRKOTTER, Monica et al. O que a formação contínua deve contemplar? O que dizem os professores. Educação \& Realidade, Porto Alegre, v. 39, n. 3, p. 849-869, 2014. Disponível em: $<$ https://doi.org/10.1590/S2175-62362014000300012>. Acesso em: 8 jul. 2020.

GALINDO, Camila J. Análise de necessidades de formação continuada de professores: uma contribuição às propostas de formação. 2011. Tese (Doutorado em Educação). Araraquara: UNESP, 2011.

GIROUX, Henry. Os professores como intelectuais: rumo a uma pedagogia crítica da aprendizagem. Tradução de Daniel Bueno. Porto Alegre: Artes Médicas, 1997.

GONZÁLEZ, Carlos V. Reflexiones y ejemplos de situaciones didácticas para una adecuada contextualización de los contenidos científicos en el proceso de enseñanza. Revista Eureka sobre Enseñanza y divulgación de las Ciencias, Cádiz, v. 1, n. 3, p. 214-223, 2004. Disponível em: <http://dx.doi.org/10.25267/Rev_Eureka_ensen_divulg_cienc.2004.v1.i3.05>. Acesso em: 11 jul. 2020.

HALMENSCHLAGER, Karine R. et al. Articulações entre educação do campo e ensino de ciências e matemática presentes na literatura: um panorama inicial. Ensaio Pesquisa em Educação em Ciências, Belo Horizonte, v. 
19, e2800, 2017. Disponível em: <https://doi.org/10.1590/1983-21172017190131>. Acesso em: 11 jul. 2020.

KATO, Danilo S.; KAWASAKI, Clarice S. As concepções de contextualização do ensino em documentos curriculares oficiais e de professores de Ciências. Ciência \& Educação, Bauru, v. 17, n. 1, p. 35-50, 2011. Disponível em: < https://doi.org/10.1590/S1516-73132011000100003>. Acesso em: 10 jul. 2020.

KOLLING, Edgar J.; NERY, Irmão; MOLINA, Monica C. Por uma educação básica do campo. Brasília: Articulação Nacional por uma Educação do Campo, 1999. (Coleção Por Uma Educação Básica do Campo, 1).

LEITE, Fabiane A.; RADETZKE, Franciele S. Contextualização no ensino de ciências: compreensões de professores da educação básica. Vidya, Santa Maria, v. 37, n. 1, p. 273-286, 2017. Disponível em: <https://periodicos.ufn.edu.br/index.php/VIDYA/article/viewFile/1560/1900>. Acesso em: 12 jun. 2019.

LIBÂNEO, José C. Adeus professor, adeus professora? Novas exigências educacionais e profissão docente. 13. ed. São Paulo: Cortez, 2011.

LIMA, Elmo S. Currículo das escolas do campo: perspectivas de rupturas e inovação. In: Ariosto M. (Orgs.). Diálogos sobre a educação do campo. 2. ed. Teresina: Edufpi, 2014, p. 107-128. ; SILVA,

; MENDES SOBRINHO, José A. C. A formação continuada de professores de ciências naturais: perspectivas para o semiárido piauiense. In: MENDES SOBRINHO, José A. C (Org.). Práticas pedagógicas em ciências naturais: abordagens na escola fundamental. Teresina: Edufpi, 2008, p. 145-168.

LIMA, Maria E. C. C.; PAULA, Helder F.; SANTOS, Mauro B. L. Ciências da vida e da natureza no curso de licenciatura em educação do campo - UFMG. In: ANTUNES-ROCHA, Maria I.; MARTINS, Aracy. (Org.). Educação do campo: desafios para a formação de professores. Belo Horizonte: Autêntica, 2009. p. 107-118.

LOPEZ, María J. D. Necesidades formativas. Modelos para su análisis y evaluación. Revista de Estudios e Investigación en Psicología y Educación, Santiago de Compostela, n. 6, p. 6-10, 2017. Disponível: <https://doi.org/10.17979/reipe.2017.0.06.2132>. Acesso em: 13 jul. 2020.

MADAUS, George F.; STUFFLEBEAM, Daniel L.; SCRIVEN, Michael. Program evaluation: a historical overview. In: MADAUS, George F.; SCRIVEN, Michael; STUFFLEBEAM, Daniel L. (Eds.). Evaluation models: viewpoints on educational and human services evaluation. Boston: Kluwer-Nijhoff Publishing, 1983, p. 3-18.

MARCONI, Marina A.; LAKATOS, Eva M. Fundamentos de metodologia científica. 5. ed. São Paulo: Atlas, 2003.

MESA, Lourdes M. et al. Análisis de necesidades en formación de profesorado. Revista de Investigación Educativa, v. 8, n. 16, p. 175-182, 1990.

McKILLIP, John. Need Analysis: Tools for the Human Services and Education. London: Sage Publ., 1987.

MINAYO, Maria C. S. Trabalho de campo: contexto de observação, interação e descoberta. In:

(Org.). Pesquisa social: teoria, método e criatividade. 28. ed. Petrópolis: Vozes, 2009. p. 61-77.

MOLINA, Monica C. Considerações finais. In: (Org.). Educação do campo e pesquisa: questões para 
reflexão. Brasília: Ministério do Desenvolvimento Agrário, 2006. p. 90, 91.

Expansão das licenciaturas em Educação do Campo: desafios e potencialidades. Educar em Revista, Curitiba, n. 55, p. 145-166, 2015. Disponível em: <https://doi.org/10.1590/0104-4060.39849>. Acesso em: 9 jul. 2020.

Contribuições das Licenciaturas em Educação do Campo para as políticas de formação de educadores. Educação \& Sociedade, Campinas, v. 38, n. 140, p.587-609, 2017. Disponível em: <https://doi.org/10.1590/es0101-73302017181170>. Acesso em: 11 jul. 2020.

; HAGE, Salomão A. M. Política de formação de educadores do campo no contexto da expansão da educação superior. Revista Educação em Questão, Natal, v. 51, n. 37, p. 121-146, 2015. Disponível em: <https://doi.org/10.21680/1981-1802.2015v51n37ID7174>. Acesso em: 7 jul. 2020.

MUNARIM, Antonio. Educação do campo: desafios teóricos e práticos. In: do campo: reflexões e perspectivas. Florianópolis: Insular, 2010. p. 9-18. et al. (Org.). Educação

PACHECO, Luci M. D. Camponês. In: STRECK, Danilo R.; REDIN, Euclides; ZIKOSKI, Jaime J. (Orgs.). Dicionário Paulo Freire. 3. ed. Belo Horizonte: Autêntica, 2017. p. 64, 65.

PARISOTTO, Ana L. V.; RINALDI, Renata P. Ensino de língua materna: dificuldades e necessidades formativas apontadas por professores na educação fundamental. Educar em Revista, Curitiba, n. 60, p. 261-276, 2016. Disponível em: <https://doi.org/10.1590/0104-4060.45125>. Acesso em: 13 jul. 2020.

PAZ, Fabio S.; USTRA, Sandro R. V. Educação do Campo: abordagens e tendências no ensino de ciências. Revista Educação e Políticas em Debate, Uberlândia, v. 7, n. 3, p. 550-562, 2018. Disponível em: <https://doi.org/10.14393/REPOD.issn.2238-8346.v7n3a2018-15>. Acesso em: 11 jun. 2020.

PINTO, Alvares V. Ciência e existência: problemas filosóficos da pesquisa científica. 3. ed. Rio de Janeiro: Paz e Terra, 1979.

RIBEIRO, Marlene. Movimento camponês, trabalho e educação: liberdade, autonomia, emancipação: princípios/fins da formação humana. 2. ed. São Paulo: Expressão Popular, 2013b.

RODRIGUES, Ângela.; ESTEVES, Manuela. A análise de necessidades na formação de professores. Porto: Porto Editora, 1993.

SILVA, Maria O. P. E. A análise de necessidades de formação na formação contínua de professores: um caminho para a integração curricular. 2000. Tese (Doutorado em Educação). São Paulo: Universidade de São Paulo, 2000.

SILVA, Adriana P. P. F. Bakhtin. In: OLIVEIRA, Luciano A. (Org.). Estudos do discurso: perspectivas teóricas. São Paulo: Parábola Editorial, 2013. p. 45-70.

SILVA, Francislene N. S. et al. Educação do Campo e ensino de Ciências no Brasil: uma revisão dos últimos dez anos. Revista Brasileira de Ensino de Ciências e Tecnologia, Ponta Grossa, v. 12, n. 1, p. 226-244, 2019. Disponível em: <https://doi.org/ 10.3895/rbect.v12n1.7547>. Acesso em: 10 jul. 2020.

SORDI, Mara R. L. Docência no ensino superior: interpelando os sentidos e desafios dos espaços institucionais de formação. Educar em Revista, Curitiba, v. 35, n. 75, p. 135-154, 2019. Disponível em: <https://doi.org/10.1590/0104-4060.67031>. Acesso em: 11 jul. 2020.

TEJEDOR, Francisco J. Perspectivas metodológicas del diagnóstico y evaluación de necesidades en el ámbito educativo. Revista de Investigación Educativa, v. 8, n. 16, p. 15-37, 1990. Disponível em: 
<http://revistas.um.es/rie/article/view/136831/124331>. Acesso em: 11 ago. 2019.

THIOLLENT, Michel. Crítica metodológica, investigação social e enquete operária. São Paulo: Polis, 1982. (Coleção Teoria e História, 6).

VOLÓCHINOV, Valentin. Marxismo e filosofia da linguagem: problemas fundamentais do método sociológico na ciência da linguagem. Tradução de Sheila Grillo e Ekaterina Vólkova Américo. 2. ed. São Paulo: Editora 34, 2018.

Submetido: $20 / 07 / 2020$

Aprovado: $19 / 12 / 2020$ 